\title{
Hubungan Tingkat Pengetahuan tentang Hipertensi dengan Perilaku Pencegahan Terjadinya Komplikasi Hipertensi
}

\author{
Nelly Sulastri S, Wahyu Hidayat, Lindriani
}

Fakultas Kesehatan, Universitas Mega Buana Palopo

\section{Info Artikel \\ Riwayat Artikel: \\ Received : 04 Desember 2021 \\ Revised : 17 Desember 2021 \\ Accepted : 28 Desember 2021}

\section{Kata Kunci:}

Tingkat Pengetahuan Perilaku Pencegahan Hipertensi

\begin{abstract}
ABSTRAK
Latar Belakang: Hipertensi merupakan penyebab penyakit yang paling sering terjadi pada kardiovaskular dan juga sebagai masalah utama di negara maju dan di negara berkembang. Penderita hipertensi kadang tidak tahu jika dirinya memiliki riwayat hipertensi dan akan segera diketahui jika terjadi beberapa komplikasi. Sebanyak 235 penderita hipertensi mengalami penyakit stroke tahun 2020. Tujuan: untuk mengetahui hubungan tingkat pengetahuan tentang hipertensi dengan perilaku pencegahan terjadinya komplikasi hipertensi di wilayah kerja puskesmas bua kabupaten luwu. Metode: Jenis penelitian ini adalah penelitian kuantitatif observasional analitik dengan desain cross sectional pada 70 responden di Wilayah kerja Puskesmas Bua. Teknik pengambilan sampel dengan menggunakan metode nonprobability sampling dengan pendekatan teknik purposive sampling. Instrumen Penelitian yang digunakan adalah kuesioner hypertension knowledge level scale dan kuesioner perilaku pencegahan terjadinya komplikasi hipertensi . Hasil: Hasil Uji Statistik Uji gamma diperoleh nilai p $=0,000(\mathrm{p}<0,05)$ maka dapat diinterpretasikan bahwa ada hubungan tingkat pengetahuan tentang hipertensi dengan perilaku pencegahan terjadinya komplikasi hipertensi. Kesimpulan: Semakin baik pengetahuan tentang hipertensi seseorang maka perilaku pencegahan terjadinya komplikasi hipertensi semakin baik pula. Oleh karena itu, disarankan kepada perawat untuk memberikan edukasi kesehatan terkait hipertensi kepada warga pada saat melakukan kegiatan seperti posbindu atau pada saat warga kontrol ke puskesmas agar kesehatan masyarakat dapat terkendali dengan baik.
\end{abstract}

This is an open access article under the CC BY-SA license.

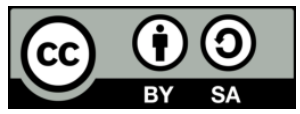

\section{Corresponding Author:}

Wahyu Hidayat

Fakultas Kesehatan, Universitas Mega Buana Palopo

Jl. Tandi Pau III No. 4, Kota Palopo, Indonesia

Email: wahyu.aries91@gmail.com

\section{PENDAHULUAN}

Hipertensi merupakan penyebab penyakit yang paling sering terjadi pada kardiovaskular dan juga sebagai masalah utama di negara maju dan di negara berkembang. Penderita hipertensi juga tidak tahu jika dirinya memiliki riwayat hipertensi dan akan segera diketahui jika terjadi beberapa komplikasi (Kemenkes, 2019). Hipertensi terjadi karena dipengaruhi oleh banyak faktor dan dapat terjadi secara cepat dan juga lambat. Hipertensi dapat disebabkan oleh beberapa faktor seperti usia, stress, obesitas, merokok, minum minuman yang beralkohol, penyakit kelainan pada ginjal dan sebagainya (Wahyuni \& Susilowati, 2018).

Beberapa komplikasi yang timbul akibat hipertensi yang tidak tertangani dengan baik diantaranya transient ischemic attack, infark miokard, diabetes melitus, chronic kidney disease dan kebutaan. Penyebab kematian tertinggi disebabkan oleh penyakit Stroke (51\%) dan Infark miokard (45\%) (Kemenkes, 2017). Angka kejadian stroke setiap tahunnya mengalami peningkatan (Permatasari, 2020).

Pengetahuan dapat meningkatkan pencegahan terjadinya stroke dengan perawatan hipertensi. Pengetahuan menjadi kebutuhan mendasar dalam upaya meningkatkan perilaku pencegahan komplikasi hipertensi. Kurangnya pengetahuan tentang komplikasi hipertensi dapat mempengaruhi perilaku pencegahan komplikasi hipertensi yang diakibatkan oleh perubahan life style, mengkonsumsi makanan yang tinggi lemak, 
merokok dan cemas yang berlebihan (Yanti et al., 2020). Beberapa penelitian menunjukkan hubungan tingkat pengetahuan dengan perilaku pencegahan terjadinya komplikasi hipertensi yang saling mempengaruhi. Penderita hipertensi yang berpengetahuan tinggi berpeluang sebesar $10,4 \%$ untuk melaksanakan dalam pencegahan komplikasi hipertensi dibandingkan dengan penderita yang berpengetahuan rendah (Simatupang, 2019; Yanti et al., 2020).

Pencegahan komplikasi hipertensi dapat dilakukan dengan meningkatkan pengetahuan. Pengetahuan yang kurang akan mempengaruhi penderita hipertensi agar dapat menangani kekambuhan atau melakukan pencegahan agar komplikasi tidak terjadi (Wahyuni \& Susilowati, 2018). Meskipun demikian hipertensi di beberapa negara tergolong tinggi. Prevalensi hipertensi tertinggi di wilayah Afrika dengan prevalensi tertinggi (27\%) dan di Negara Swiss memiliki prevalensi hipertensi terendah (18\%) (World Health Organization, 2021).

Data Nasional menunjukkan bahwa prevalensi hipertensi berdasarkan hasil pengukuran pada penduduk usia $\geq 18$ tahun sebesar $34,1 \%$, penderita hipertensi tertinggi berada di Kalimantan Selatan $(44,1 \%)$, dan penderita hipertensi terendah berada di Papua $(22,2 \%)$. Estimasi jumlah kasus hipertensi di Indonesia sebesar 63.309.620 orang, kematian yang terjadi karena hipertensi sebanyak 427.218 orang (Kemenkes, 2019). Khusus di Sulawesi Selatan persentase pelayanan pemeriksaan hipertensi di tahun 2019 sebanyak 25,06\%, dengan pelayanan tertinggi di Kabupaten Bantaeng 100\% dan Kabupaten Pinrang 87,67\%. Jumlah estimasi penderita hipertensi di atas 15 tahun di Sulawesi Selatan berkisar 1.520 .659 penderita dengan pelayanan sebanyak 381.133 orang (Dinkes, 2020).

Puskesmas Bua di Kabupaten Luwu merupakan salah satu puskesmas yang jumlah penderita hipertensinya cukup tinggi yakni 1255 penderita pada tahun 2020 yang merupakan penyakit tertinggi yang diderita pasien. Setelah melakukan wawancara dengan petugas kesehatan, mengatakan bahwa pasien yang menderita penyakit hipertensi telah mengalami komplikasi dan rata-rata komplikasi yang dirasakan pada penderita hipertensi yaitu stroke. Sebanyak 235 penderita hipertensi mengalami penyakit stroke tahun 2020. Oleh karena itu tujuan penelitian ini adalah untuk mengetahui hubungan tingkat pengetahuan tentang hipertensi dengan perilaku pencegahan terjadinya komplikasi hipertensi.

\section{METODE PENELITIAN}

Desain Penelitian ini adalah penelitian kuantitatif observasional analitik dengan desain Cross sectional yaitu penelitian yang hanya diamati saja tanpa melakukan intervensi dimana variabel Independen dan Dependen diukur hanya satu kali dengan waktu yang bersamaan. Populasi yang digunakan dalam penelitian ini adalah masyarakat yang menderita hipertensi sebanyak 235 orang, Teknik pengambilan sampel menggunakan purposive sampling dengan jumlah sampel yang didapatkan sebanyak 70 responden. Kuesioner yang digunakan adalah kuesioner hypertension knowledge level scale dan kuesioner perilaku pencegahan terjadinya komplikasi hipertensi (Fajarsari et al., 2020). Uji statistik yang digunakan dalam penelitian adalah Uji Gamma.

\section{HASIL}

\subsection{Karakteristik Responden}

Tabel 1. Distribusi Frekuensi Responden Berdasarkan Kelompok Umur

\begin{tabular}{ccc}
\hline Tahun & Frekuensi (f) & Persentase (\%) \\
\hline $22-28$ & 9 & 12.9 \\
$29-35$ & 12 & 17.1 \\
$36-42$ & 11 & 15.7 \\
$43-49$ & 11 & 15.7 \\
$50-56$ & 11 & 15.7 \\
$57-63$ & 15 & 21.4 \\
$64-70$ & 1 & 1.4 \\
\hline Total & $\mathbf{7 0}$ & $\mathbf{1 0 0 . 0}$ \\
\hline
\end{tabular}

Berdasarkan tabel 1, kelompok Umur menunjukkan bahwa dari 70 responden yang diteliti, jumlah responden yang paling banyak adalah kelompok umur 57-63 tahun yaitu (21,4\%), dan yang berusia 64-70 tahun adalah paling sedikit yaitu $1(1,4 \%)$. 
Tabel 2. Distribusi Frekuensi Responden Berdasarkan Jenis Kelamin

\begin{tabular}{ccc}
\hline Jenis Kelamin & Frekuensi (f) & Persentase (\%) \\
\hline Laki-laki & 23 & 32.9 \\
Perempuan & 47 & 67.1 \\
\hline Total & $\mathbf{7 0}$ & $\mathbf{1 0 0 . 0}$ \\
\hline
\end{tabular}

Berdasarkan tabel 2, kelompok Jenis kelamin menunjukkan bahwa dari 70 responden yang diteliti, jumlah responden yang paling banyak adalah responden yang berjenis kelamin perempuan sebanyak 47 responden $(67,1 \%)$, dan responden yang berjenis kelamin laki-laki yaitu 23 responden $(32,9 \%)$.

Tabel 3. Distribusi Frekuensi Responden Berdasarkan,Tingkat Pendidikan, dan pekerjaan

\begin{tabular}{ccc}
\hline Pendidikan & Frekuensi (f) & Persentase (\%) \\
\hline Tidak Sekolah & 2 & 2.9 \\
SD & 14 & 20.0 \\
SMP & 20 & 28.6 \\
SMA & 26 & 37.1 \\
Perguruan Tinggi & 8 & 11.4 \\
\hline Total & $\mathbf{7 0}$ & $\mathbf{1 0 0 . 0}$ \\
\hline
\end{tabular}

Berdasarkan tabel 3, kelompok Tingkat pendidikan responden yang paling dominan adalah SMA sebanyak $26(37,1 \%)$ orang, sedangkan yang paling sedikit adalah responden yang tidak sekolah sebanyak 2 $(2,9 \%)$ orang.

Tabel 4. Distribusi Frekuensi Responden Berdasarkan Pekerjaan

\begin{tabular}{ccc}
\hline Pekerjaan & Frekuensi (f) & Persentase (\%) \\
\hline IRT & 30 & 42.9 \\
Petani & 3 & 4.3 \\
Pegawai Swasta & 20 & 28.6 \\
Guru & 4 & 5.7 \\
Nelayan & 9 & 12.9 \\
Tidak Bekerja & 3 & 4.3 \\
Perawat & 1 & 1.4 \\
\hline Total & $\mathbf{7 0}$ & $\mathbf{1 0 0 . 0 0}$ \\
\hline
\end{tabular}

Berdasarkan tabel 4, kelompok responden berdasarkan pekerjaan paling dominan adalah IRT sebanyak $30(42,9 \%)$ orang, sedangkan yang paling sedikit adalah responden yang bekerja sebagai perawat sebanyak $1(1,4 \%)$ orang.

\subsection{Analisis Univariat}

Tabel 5. Distribusi Frekuensi Responden Berdasarkan Tingkat Pengetahuan

\begin{tabular}{ccc}
\hline Pengetahuan & Frekuensi (f) & Persentase $(\%)$ \\
\hline Tinggi & 40 & 57.1 \\
Sedang & 25 & 35.7 \\
Rendah & 5 & 7.1 \\
\hline Total & $\mathbf{7 0}$ & $\mathbf{1 0 0 . 0}$
\end{tabular}

Berdasarkan tabel 5, tingkat pengetahuan paling dominan adalah tingkat pengetahuan yang tinggi sebanyak $40(57.1 \%)$ orang, sedangkan yang paling sedikit adalah responden yang berpengetahuan rendah sebanyak 5 (7,1\%) orang, Adapun responden yang berpengetahuan sedang sebanyak $25(35,7 \%)$ orang. 
Tabel 6. Distribusi Frekuensi Responden berdasarkan Perilaku

\begin{tabular}{ccc}
\hline Perilaku & Frekuensi (f) & Persentase (\%) \\
\hline Baik & 30 & 42.9 \\
Cukup & 26 & 37.1 \\
Kurang & 14 & 20.0 \\
\hline Total & $\mathbf{7 0}$ & $\mathbf{1 0 0 . 0}$ \\
\hline
\end{tabular}

Berdasarkan tabel 6, perilaku paling dominan adalah Baik sebanyak 30 (42,9\%) orang, sedangkan yang paling sedikit adalah responden yang berperilaku kurang sebanyak 14 (20\%) orang. Adapun responden yang berperilaku cukup sebanyak $26(37,1 \%)$ orang.

\subsection{Analisis Bivariat}

Tabel 7. Analisis Hubungan Tingkat Pengetahuan dengan perilaku pencegahan terjadinya komplikasi hipertensi

\begin{tabular}{|c|c|c|c|c|c|c|c|c|c|}
\hline \multirow{4}{*}{$\begin{array}{c}\text { Tingkat } \\
\text { Pengetahuan }\end{array}$} & \multicolumn{8}{|c|}{ Perilaku Pencegahan Terjadinya Komplikasi } & \multirow{3}{*}{$\begin{array}{c}\text { Nilai } \\
\boldsymbol{\rho}\end{array}$} \\
\hline & \multicolumn{8}{|c|}{ Hipertensi } & \\
\hline & \multicolumn{2}{|c|}{ Baik } & \multicolumn{2}{|c|}{ Cukup } & \multicolumn{2}{|c|}{ Kurang } & \multicolumn{2}{|c|}{ Total } & \\
\hline & $\mathrm{n}$ & $\%$ & $\mathrm{n}$ & $\%$ & $\mathrm{n}$ & $\%$ & $\mathrm{~N}$ & $\%$ & \\
\hline Tinggi & 25 & 36 & 12 & 17.14 & 3 & 4.28 & 40 & 57.42 & \\
\hline Sedang & 5 & 7.14 & 12 & 17.14 & 8 & 11.42 & 25 & 35.7 & 0.000 \\
\hline Rendah & 0 & 0 & 2 & 3 & 3 & 4.28 & 5 & 7.28 & \\
\hline \multicolumn{7}{|c|}{ Total } & 70 & 100 & \\
\hline
\end{tabular}

Uji bivariat yang dilakukan dalam penelitian ini menggunakan Uji Gamma dimana uji tersebut digunakan untuk mengetahui hubungan antara variabel independen dan variabel dependen yaitu tingkat pengetahuan dengan perilaku pencegahan terjadinya komplikasi hipertensi di Wilayah Kerja Puskesmas Bua. Dari Hasil Statistik dengan menggunakan uji gamma didapatkan hasil nilai $\mathrm{p}=0.000$ dan $\alpha=0,05$ sehingga $\mathrm{p}<\alpha$. Hasil ini bermakna bahwa ada hubungan tingkat pengetahuan tentang hipertensi dengan perilaku pencegahan terjadinya komplikasi hipertensi.

\section{DISKUSI}

Setelah dilakukan uji statistik menggunakan uji gamma didapatkan hasil nilai $P=0.000$ yang berarti terdapat hubungan tingkat pengetahuan tentang hipertensi dengan perilaku pencegahan terjadinya komplikasi hipertensi. Hal ini menunjukkan bahwa terdapat hubungan antara tingkat pengetahuan dengan perilaku pencegahan terjadinya komplikasi hipertensi di wilayah kerja Puskesmas Bua. Hal ini dapat dimaknai bahwa dengan pengetahuan yang berbeda dapat melakukan tindakan pencegahan komplikasi hipertensi yang berbeda pula. Dimana jika individu berpengetahuan yang baik akan berpengaruh juga terhadap perilaku pencegahan terjadinya hipertensi yang baik, karena jika individu berpengetahuan dengan baik maka akan terjadi peningkatan perilaku kesehatan dalam diri seseorang untuk mengatasi pencegahan pada hipertensi (Fajarsari et al., 2020).

Pengetahuan akan semakin berkembang karena manusia memiliki kemampuan untuk berfikir dan mempunyai rasa ingin tahu yang tinggi. Akan tetapi keingintahuan yang erat memerlukan cara yang sistematis sehingga memperoleh sebuah pengetahuan (Kurniawan, 2021). Dengan pengetahuan yang meningkat maka akan terjadi peningkatan terhadap derajat kesehatan dalam diri individu yang berdasarkan kesadaran dan kemauan individu untuk mencegah suatu penyakit (Nixon, 2018).

Perilaku merupakan gabungan segala faktor yang saling berinteraksi. Interaksi ini sangat kompleks yang menyebabkan seseorang tidak menyadari telah mengaplikasikan perilaku tertentu. Sebelum mengubah perilaku individu, penting untuk mengetahui alasan seseorang dalam berperilaku (Wawan, 2011). Faktor perilaku kesehatan penting dalam pencegahan hipertensi. Faktor perilaku kesehatan meliputi faktor personal dan faktor situasional. Faktor personal meliputi faktor biologis dan faktor sosial psikologis, sedangkan faktor situasional meliputi faktor ekologis, lingkungan rumah, teknologi dan sosial budaya (Riyadina et al., 2019). 
Hasil penelitian ini ditunjang oleh beberapa temuan sebelumnya. Terdapat hubungan tindakan pencegahan komplikasi hipertensi antara penderita yang berpengetahuan rendah dan penderita yang berpengetahuan tinggi (Yanti et al., 2020). Penelitian ini menyatakan bahwa perilaku pencegahan dipengaruhi oleh pengetahuan, semakin baik pengetahuan yang dimiliki maka perilaku pencegahan juga semakin baik (Ardhiatma, 2017). Oleh karena itu, peneliti berasumsi bahwa perilaku yang baik dari responden dalam pencegahan komplikasi hipertensi, sangat dipengaruhi oleh pengetahuan mereka yang baik tentang hipertensi.

\section{KESIMPULAN}

Berdasarkan hasil penelitian dapat disimpulkan sebagian besar responden berpengetahuan tinggi tentang hipertensi dan telah banyak dari mereka yang telah menerapkan perilaku yang baik dalam pencegahan terjadinya komplikasi hipertensi. Oleh karena itu, disarankan kepada perawat untuk memberikan edukasi kesehatan terkait hipertensi kepada warga pada saat melakukan kegiatan seperti posbindu atau pada saat warga kontrol ke puskesmas agar kesehatan masyarakat dapat terkendali dengan baik.

\section{REFERENSI}

Ardhiatma, F. (2017). Hubungan Antara Pengetahuan Tentang Gout Arthitis Terhadap Perilaku Pencegahan gout Arthitis Pada Lansia. Global Health Science, 2(2), 111-116. http://jurnal.csdforum.com/index.php/ghs

Dinkes. (2020). Profil Dinkes Sul-sel. http://dinkes.sulselprov.go.id/

Fajarsari, Y., Sarjana, P., Keperawatan, T., Keperawatan, J., Kesehatan, P., \& Kesehatan, K. (2020). Hubungan tingkat pengetahuan tentang hipertensi dengan perilaku pencegahan terjadinya hipertensi pada jemaah haji di wilayah kerja puskesmas kotagede i yogyakarta.

Kemenkes. (2017). Sebagian besar penderita hipertensi tidak menyadarinya. $17 \quad$ Mei. https://www.kemkes.go.id/article/view/17051800002/sebagian-besar-penderita-hipertensi-tidak-menyadarinya.html

Kemenkes. (2019a). Hari Hipertensi Dunia 2019: "Know Your Number, Kendalikan Tekanan Darahmu dengan CERDIK.”. http://www.p2ptm.kemkes.go.id/kegiatan-p2ptm/dki-jakarta/hari-hipertensi-dunia-2019-know-yournumber-kendalikan-tekanan-darahmu-dengan-cerdik

Kemenkes. (2019b). Hipertesni penyakit paling banyak diidap masyarakat. 17 Mei 2019. https://www.kemkes.go.id/article/view/19051700002/hipertensi-penyakit-paling-banyak-diidap-masyarakat.html

Kurniawan, D. W. (2021). Metodologi Penelitian Kesehatan dan Keperawatan (A. Rahmawati (ed.); 1st ed.). Rumah Pustaka. https://books.google.co.id/books?id=CQAoEAAAQBAJ

Nixon, M. (2018). Hubungan Pengetahuan Dan Sikap Lansia Dengan Pencegahan Hipertensi Di Desa Gotting Sidodadi Kabupaten Asahan. Ocean Modelling, 22(3), 1361-1369.

Permatasari, N. (2020). Perbandingan Stroke Non Hemoragik dengan Gangguan Motorik Pasien Memiliki Faktor Resiko Diabetes Melitus dan Hipertensi. Jurnal Ilmiah Kesehatan Sandi Husada, 11(1), $298-304$. https://doi.org/10.35816/jiskh.v11i1.273

Riyadina, W., Martha, E., \& Anwar, A. (2019). Perilaku Pencegahan Dan Pengendalian Hipertensi : Studi Pengetahuan, Sikap, Perilaku (Psp) Dan Kesehatan Lingkungan Pada Wanita Pasca Menopause Di Kota Bogor. Jurnal Ekologi Kesehatan, 17(3), 182-196. https://doi.org/10.22435/jek.17.3.666.182-196

Simatupang, D. (2019). Hubungan sikap penderita hipertensi dengan pencegahan komplikasi hipertensi di poliklinik penyakit dalam RSUP H. Adam Malik Medan tahun 2019.018.

Wahyuni, W., \& Susilowati, T. (2018). Hubungan Pengetahuan, Pola Makan Dan Jenis Kelamin Terhadap Kejadian Hipertensi Di Kalurahan Sambung Macan Sragen. Gaster, 16(1), 73. https://doi.org/10.30787/gaster.v16i1.243

Wawan. (2011). Teori \& pengukuran pengetahuan, sikap, dan perilaku manusia (II). Nuha medika.

World Health Organization. (2021). Hypertension. 2021. https://www.who.int/news-room/fact-sheets/detail/hypertension

Yanti, S. E., Asyrofi, A., \& Arisdiani, T. (2020). Hubungan tingkat pengetahuan komplikasi hipertensi dengan tindakan pencegahan komplikasi. Jurnal Keperawatan, 12(3), 439-448. 